\title{
Biochemical and color changes of fresh-cut melon (Cucumis melo L. cv. Galia) treated with UV-C Rezzan KASIM ${ }^{1 \star}$, Mehmet Ufuk KASIM ${ }^{1}$
}

\begin{abstract}
The importance of minimally processed commodities in the retail groceries of most developed countries has been rising continuously during the last decades. Cantaloupe melon is used more than any other fruit in fresh-cut processing. Ultraviolet (UV) light has been extensively used to simulate biological stres in plants and for determining resistance mechanisms of plant tissues. In this study the effect of ultraviolet irradiation on some properties of fresh-cut cantalope melon was determined during storage. Freshly cut cantalope melons cubes treated with ultraviolet irradiation at the doses of 1,2 or 3 min before storage, and then placed in a cold room at $5 \pm 1^{\circ} \mathrm{C}$ temperature and $85-90 \% \mathrm{RH}$. Hue angle values of control group is low compared to UV-C treated samples, whereas L values of is high. EL of UV treated samples higher than those of control group. Total soluble solids of fresh-cut melon samples in UC3 treatment increased during storage. The results indicate that UV-C treatments on fresh-cut cantaloupe melon cubes increased total soluble solids independently from water loss.
\end{abstract}

Keywords: cantaloupe; minimally processing; total soluble solids; hue angle value; $\mathrm{L}^{*}$ value; electrolyte leakage.

\section{Introduction}

Melon (Cucumis melo L.) is one of the most important fruiting vegetables that consumed all over the world. Also, fresh-cut melons are a common component of fresh-cut fruit product. Quality retention and shelf-life extension of freshcut products are important for the industry because of their economic impact. Fresh-cut fruits and vegetables with high $\mathrm{pH}(>4.6)$ and water activity (aw $>0.85$ ) are considered to be highly perishable when they are not subjected to preservative processes delay undesirable biological and biochemical changes (Wiley, 1994).

Therefore it is important that treatments applied to freshcut fruits help maintain their appearance (i.e. color, integrity, absence of excessive dripping in the package), as this is the first characteristic a consumer perceives as quality of the product. Change in texture, flavor, color and appearance are the limiting factors of minimally processed products quality which have been reported in melon fruits (Portela \& Cantwell, 1998; Lamiranka et al., 2003; Ergun et al., 2007).

The quality of fresh-cut cantaloupe changes rapidly during storage (Lamiranka et al., 2000). Changes in texture and flavor are the main factors limiting of quality minimally processed cantaloupe melon (Aguayo et al., 2004). Portela \& Cantwell (2001), had reported that, however, there were no changes aroma, off-odor, and total sugar in minimally processed cantaloupe melon but the texture significantly declined during storage.

Fresh-cut cantaloupe shelf-life may be extended by using modified atmospheres (Cantwell et al., 1996; O'ConnorShaw et al., 1996), calcium chloride dips alone or in combination with heat treatments (Luna-Guzmán et al., 1999), calcium lactate treatment (Luna-Guzmán \& Barrett, 2000), and also UV treatment (Lamiranka et al., 2002, 2005; Turtoi, 2013).

Ultraviolet (UV) technology is widely used as an alternative to chemical sterilization and reduction of vegetative organisms in food products. Ultraviolet light also induces biological stres in plants and defense mechanisms of plant tissues with the consequent production of phytoalexin compounds (Mercier, 1997).

The objective of this study is to determine changes in color, total soluble solids, electrolyte leakage, induced by stres conditions in fresh-cut cantaloupe melon cubes.

\section{Materials and methods}

\subsection{Plant material}

Galia melon fruits (Cucumis melo L. reticulata) were obtained from the Kocaeli Wholesale Distribution Center. Melons were screened for uniformity, such as being free from any mechanical damage and diseases and also same stage of maturity.

\subsection{Sample preparation}

Melon fruits were cut into half with a sharp knife, and seeds and placental tissue removed, each half sliced once longitudinally with a sharp knife. Then, the fruit slices were cut into cubes approximately $1.5 \times 1.5 \times 1.5 \mathrm{~cm}^{3}$ in size. The experiment was established with 3 replications, and for each replicates, six melon cubes (approximately 80-90 g melon cubes for each dishes) were placed in polystyrene foam dishes and wrapped with stretch film.

${ }^{1}$ Kocaeli University, Vocational School of Arslanbey, Graduate School of Natural and Applied Sciences, Kartepe, Kocaeli, Turkey, e-mail: rkasim@kocaeli.edu.tr 


\subsection{Ultraviolet Irratiation (UV-C) treatments}

The UV-C radiation device consisted of two banks of three stainless-steel reflectors with unfiltered germicidial emitting lamps (TUV $30 \mathrm{~W} / \mathrm{T} 8$ Philips, Holland) located $30 \mathrm{~cm}$ above the radiation vessel. Prior to use, the lamps were allowed to stabilize by turning them on the least 15 min. Packaged melons were placed on upper surfaces at a distance of $30 \mathrm{~cm}$ from the screen. Radiation of the product was carried out in the cold room at $5^{\circ} \mathrm{C}$ to avoid a temperature increase during treatments. $\mathrm{UV}-\mathrm{C}$ measurements were taken with radiometer to determine the spectral irradiance of the bare lamp. The integral value of spectral irradiance for the wavelenght range of 250-280 nm was as $7166 \mathrm{~mW} \mathrm{~m}^{-2}$.

UV-C treatments used were; control (C, non treated), UV-C irradiation for 1 minute (UC1), UV-C irradiation for 3 minutes (UC3), and UV-C treatment for $5 \mathrm{~min}$ (UC5).

\subsection{Storage conditions}

After irradiation, fresh-cut melons (six cubes per dishes for each replicate) were stored in a cold room set at $5 \pm 1^{\circ} \mathrm{C}$ temperature and $85-90 \% \mathrm{RH}$.

\section{Flesh color}

The color attibutes $\mathrm{L}^{\star} \mathrm{a}^{\star} \mathrm{b}^{\star}$ each melon cubes were measured using a chromameter (Model CR 400, Conica-Minolta, Osaka, Japan), equipped with an $8 \mathrm{~mm}$ measuring head and a D65 illuminant. The chromameter was calibrated against a white tile. The melon flesh were measured for $\mathrm{L}^{*}$ (lightness), $\mathrm{a}^{*}$ (green $(-)$ tor ed $(+)), b^{\star}$ (blue $(-)$ to yellow $(+)$. Hue angle $\left(\mathrm{h}^{\circ}=\tan ^{-1}\right.$ $\left(b^{*} / a^{*}\right.$ when $\mathrm{a}^{\star}>0$ and $\mathrm{b}^{*}>0$ or $\mathrm{h}^{\circ}=180^{\circ}+\tan ^{-1}\left(\mathrm{~b}^{\star} / \mathrm{a}^{\star}\right)$ when $\mathrm{a}^{\star}<0$ or $b^{\star}>0$ ) was calculated from $a^{\star}$ and $b^{\star}$ values.

\section{Electrolyte Leakage (EL)}

Electrolyte leakage was measured as fruit discs $(5 \mathrm{~mm}$ diameter) cut out of the fruit. The discs were washed several times in distilled water and then incubated in distilled water. Conductivity was measured after $2 \mathrm{~h}$ of incubation. Total electrolyte conductivity in the discs was measured afted they had been frozen and thawed. Electrolyte leakage was calculated as a percentage of conductivity after they had been frozen and thawed. Electrolyte leakage was calculated as a percentage of conductivity after $2 \mathrm{~h}$ of total (Kasım \& Kasım, 2008).

\section{Total soluble solids}

Juice extracted from cubes of fresh-cut cantaloupe was used to assay soluble solids content and was evaluated using a hand refractometer at $20^{\circ} \mathrm{C}$.

\section{Weight loss}

Three replicated per treatment were weighed at the beginnig and the during of storage. The weight loss (\%) was calculated in reference to initial weight of the fresh-cut melon cubes.

\section{Statistical analysis}

Statistical analysis performed on data included analysis of variance (ANOVA) and differences among means determined by Duncan's multiple range test with significance defined at $\mathrm{p}<0.05$. The experimental design used for analytical measurements was completely randomized and repeated three times.

\section{Results and discussions}

\subsection{Total Soluble Solids (TSS)}

TSS content of fresh-cut melon cubes in control and UC5 decreased during storage, while UC1 and UC3 increased (Figure 1). Also, TSS of samples in UC3 treatment was higher than that of the other treatment groups during storage, and differences among the treatments were significant statistically $(\mathrm{p}<0.05)$ at the end of the storage. Supapwanich \& Tucker $(2011)$ were found that soluble solids content of fresh-cut Honeydew melon fruit remained constant and was about $10.9^{\circ}$ Brix during storage. But in the present study, in Galia melon cultivar, TSS level of samples appoximately $8.4 \%$ at the beginning of storage and decreased during the storage except for UC1 and UC3. Cutting induces degradative changes associated with plant tissue senescence, and a consequently decrease in shelf life of fresh-cut product compared to the unprocessed product. As a part of defence mechanism, plant tissues frequently produced compounds such as phytoalexins, but synthesis of these naturally occuring compounds might be slow (Lamiranka et al., 2002). Ultraviolet irradiation has thus been extensively used to stimulate biological stres in plants and for determining resistance mechanism of plant tissues (Mercier, 1997). In this study, total soluble solids content of control group and UC5 decreased, but it has increased in UC1 and UC3 applications. So it might be said that, lower doses of ultraviolet irradiation has encouraged starch-soluble sugar conversion but in higher doses did not effect. Also, different crops give respond to different against to UV-C treatments. For example UV-C radiation (60s and 90s) significantly inhibited the decrease in the firmness, TSS and sugar reduction and the increasing rate of titratable acidity in the fresh-cut pineapples has been found by Pan \& Zu (2012).

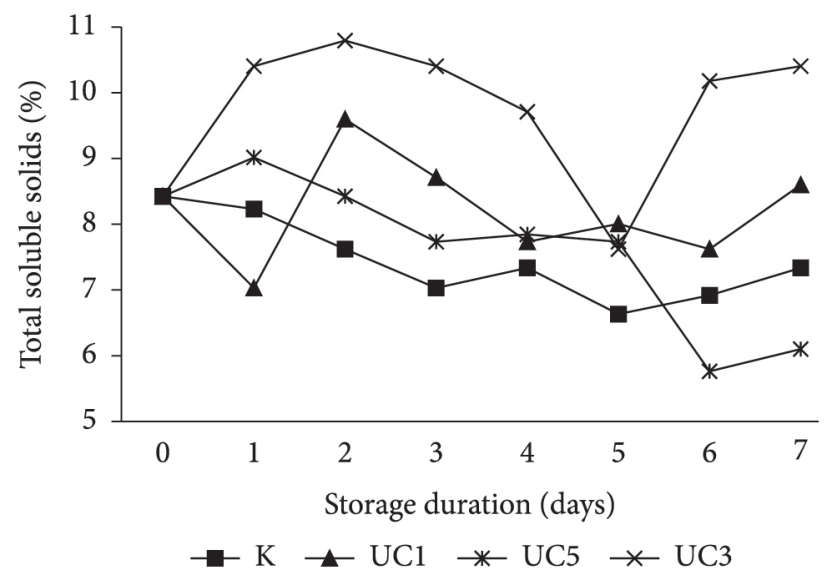

Figure 1. Total soluble solids (TSS) content of fresh-cut melon cubes treated with different ultraviolet (UV-C) irradiation doses. 


\subsection{Hue angles}

Hue angles values of samples treated with different doses of ultraviolet irradiation were given in Figure 2. As shown in Figure 2, hue angle values of control group were decreased during storage. But, hue values of samples in UC3 and UC5 treatments increased first 2 days of storage, and then decreased. Hue values of UC1 treatment, however, showed irregular change. Hue angle values of samples in control group were found 97.51 and followed by UC1 (99.30), UC2 (101.21) and UC5 (103.66) at respectively, and also differences between UC3 or UC5 and UC1 or control were significant statistically at the days of $3^{\text {rd }}$. Hue angles values of samples in UC1 treatment were found the lowest, and differences between UC1 and the other treatments were statistically significant $(\mathrm{p}<0.05)$ at the end of the storage. Color is important component of visual appearance (Clydesdale, 1991), and hue angle value shows true color of samples. Hue angle values of samples in control group decreased during storage compared to UV-C treated samples. Therefore it is showed that color of samples in control group started to change from green to light green-yellow-orange. So, it suggests that the UV-C treatments slowed degradation of chlorophyll especially higher doses. These findings are compatible with the results found by Chisari et al. (2011), that the lowest perceptible color variation, expressed as $\mathrm{DE}^{*}$, was in the samples exposed to 120 $s$ radiation $(\mathrm{DE}=8.58)$, while the highest value was noticed in

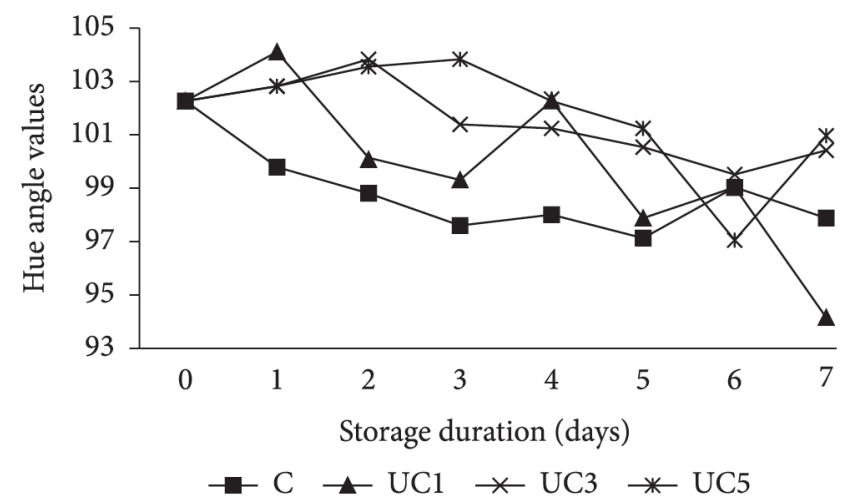

Figure 2. Hue angle values of fresh-cut melon cubes treated with different ultraviolet (UV-C) irradiation doses.

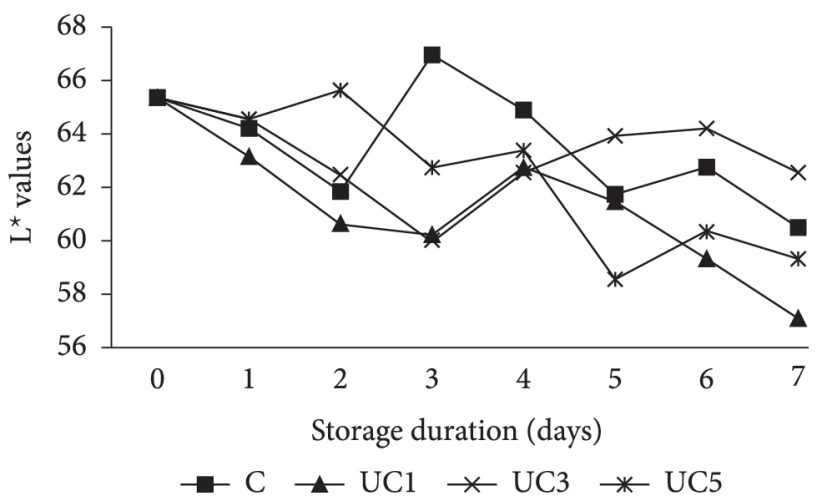

Figure 3. $L^{\star}$ values of fresh-cut melon cubes treated with different ultraviolet (UV-C) irradiation doses. the untreated Galia melon sample $(\mathrm{DE}=6.11)$. So, results of hue angle measurement shown that, color changes of fresh-cut melon cubes decrease by ultraviolet $\mathrm{C}$ irradiation.

\section{$3.3 L^{\star}$ values}

Luminosity $\left(\mathrm{L}^{*}\right)$ of fresh-cut melon cubes decreased in all treatment groups (Figure 3) compared to initial values. $\mathrm{L}^{*}$ values of samples in control group was higher than that of UV-C treated samples during the 3 rd days of storage. Also the differences between control group and UV-C treated samples was found statistically significant $(p<0.05)$. The decrease in $L^{*}$ values indicates that color of samples changed from green to light green-yellow-orange. Because in CIE Lab system; reduction of $\mathrm{L}^{*}$ values shows that color of samples is darkening; while increasing $\mathrm{L}^{\star}$ values represent decolorization of samples. Previous studies it was found that, increasing lightness $\left(\mathrm{L}^{*}\right)$ value of samples during storage shows that browning reaction did not occured in minimally processed cantaloupe melons during storage (Lamiranka et al., 2000). In the present study, $\mathrm{L}^{*}$ values of samples in all groups decreased but browning did not take place in any of the treatment groups.

\section{$3.4 b^{\star}$ values}

As shown in Figure 4, $\mathrm{b}^{*}$ values of fresh-cut melon cubes in UC3 treatment was lower (15.03) than UC1 (17.80), UC3 (18.68) and control (20.70), respectively. Also differences between UC3 treatment and other groups was found statistically significant $(\mathrm{p}<0.05)$ at the day of $3^{\text {rd }}$. At the begining of storage, fresh-cut Galia melon cubes which has green color, later the green color is started change from green to light green-yellow-orange in control group. But color of UV-C treated samples did not change and remained green, and this is supported by results of $b^{\star}$ values. Therefore it might be said that color changes in fresh-cut melon cubes is delayed by UV-C treatments.

\subsection{Electrolyte Leakage (EL)}

EL level of samples in all groups increased during storage (Figure 5). But the increase rate of EL is high in UV-C treated samples especially UC3 than control group, and differences between UC3 and than other treatment were significant

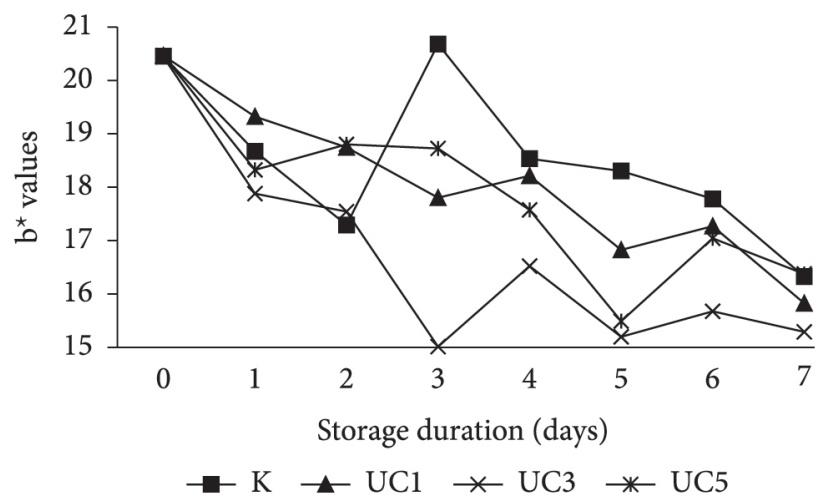

Figure $4 . b^{*}$ values of fresh-cut melon cubes treated with different ultraviolet (UV-C) irradiation doses. 


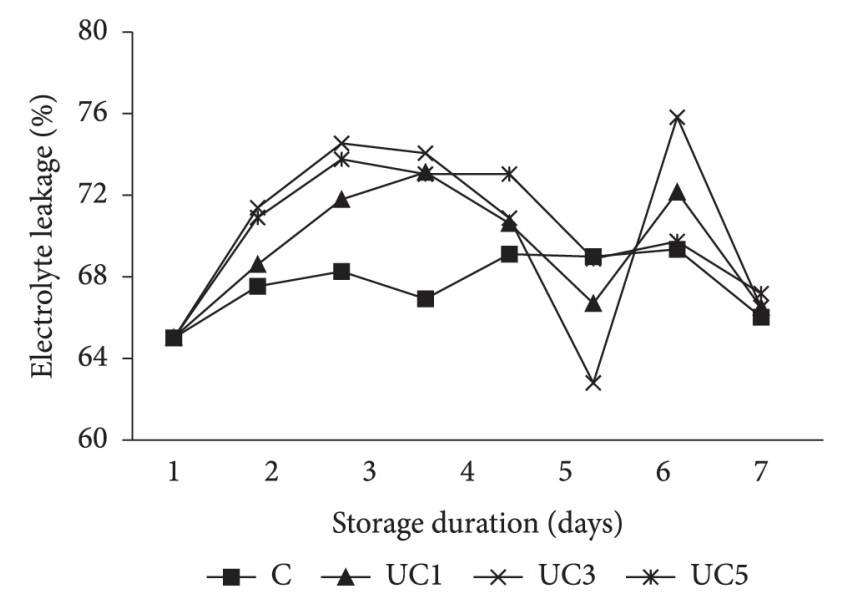

Figure 5. Electrolyte leakage of fresh-cut melon cubes treated with different ultraviolet (UV-C) irradiation doses.

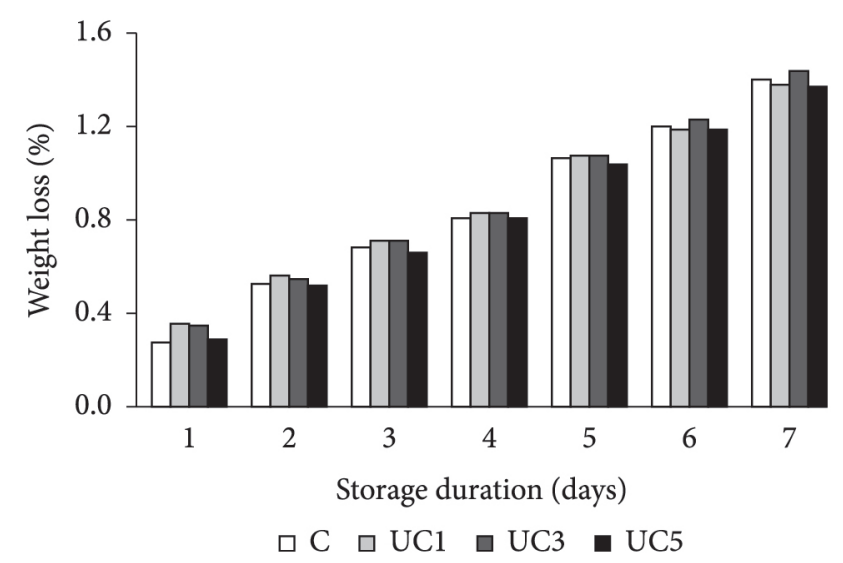

Figure 6. Weight loss of fresh-cut melon cubes treated with different ultraviolet (UV-C) irradiation doses.

statistically $(\mathrm{p}<0.05)$ at the day of 6 . In earlier studies by Supapwanich \& Tucker (2011), similar result was also found. UV treatments, especially higher doses has harmful effect on plant tissues. In this study, EL values of samples treated with UV-C found to be high compared to control. Therefore it might be said that UV-C applications on tissue of fresh-cut melon is harmful effect. Ergun et al. (2007) reported that the loss of firmness in fresh-cut Galia melon associated with an increase in electrolyte leakage. In this study it was found an increase of total soluble solids content of UV-C treated samples compared to control group. So, ripening of fresh-cut melon was increased by UV-C treatment. Also, firmness value of samples treated with UV-C was low compared to control (data not shown). Therefore, our results agreed with Ergun et al. (2007).

\subsection{Weight loss}

Weight loss of samples in all group increased during storage (Figure 6). Also, the increase was low in UC5 group compared to other treatments. But differences among the treatments had no significant statistically.
Since fresh-cut products lose their integrity after peeling, cutting, slicing and shredding, they tends to be more vulnerable to water losses. Also peel or skin, is a very important barrier to loss of turgor and against desiccation (Garcia \& Barrett, 2002). Water losses of 3 and $5 \%$ in spinach and apple, respectively makes these products unmarketable (Sams, 1999). In the present study it found that water loss of fresh-cut melon cubes was low and it did not exceed neither 3 nor $5 \%$, therefore salable qualities of samples did not decreased.

\section{Conclusions}

In this study, the effect of ultraviolet irradiation (UV-C) treatments on the quality of fresh-cut cantaloupe melon was investigated. UV-C treatments have been effective on the retention of color of samples. Similarly, the levels of total soluble solids of samples treated with UV-C especially UC3 doses. But UV-C applications on tissue of fresh-cut melon is harmful effect. Hence, it is suggested that UV-C treatments of fresh-cut melons are effective to improved total soluble solids and color characteristics.

\section{References}

Aguayo, E., Escalona V. H., \& Artes, F. (2004). Metabolic behavior and quality changes of whole and fresh processed melon. Journal of Food Science, 69(4), 148-155.

Cantwell, M., Lopez-Galvez, G., Rovelo-Gonzalez, J., \& Nie, X. (1996). Factors affeting quality of minimally processed cantaloupe melon. I. Temperatire and atmosphere. In Abstract of the Annual Meeting and Food Expo, New Orleans, USA. Institute of Food Technologists. $40 \mathrm{E}-10$.

Chisari, M., Barbagallo, R. N., Spagna, G., \& Artes, F. (2011). Improving the quality of fresh-cut melon through inactivation of degradative oxidase and pectinase enzymatic activities by UV-C treatment. International Journal of Food Science and Technology, 46(3), 463-468. http://dx.doi.org/10.1111/j.1365-2621.2010.02466.x

Clydesdale, F. M. (1991). Color as a factor in food choice. Critical Reviews in Food Science and Nutrition, 33(1), 83-101. PMid:8424857. http://dx.doi.org/10.1080/10408399309527614

Ergun, M., Jeong, J., Huber, D. J., \& Cantliffe, D. J. Physiology of freshcut 'Galia' (Cucumis melo var. Reticulates) from ripe fruit treated with 1-methylcyclopropene. Postharvest Biology and Technology, 44(3), 286-292, 2007. http://dx.doi.org/10.1016/j.postharvbio.2006.08.019

Garcia, E., \& Barrett, D. (2002). Preservative treatments for fresh-cut fruits and vegetables. In O. Lamiranka (Ed.), Fresh-cut fruits and vegetables: science, technology, and market. Boca Raton: CRC Press.

Kasim, R., \& Kasim, M. U. (2008). The effect of ultraviolet irradiation (UV-C) on chilling injury of cucumbers during cold storage. Journal of Food, Agriculture \& Environment, 6(1), 50-54.

Lamiranka, O., Chen, J. C., Banks, D., \& Hunter, P. A. (2000). Biochemical and microbial changes during the storage of minimally processed cantaloupe. Journal of Agricultural and Food Chemistry, 48(12), 955-961.

Lamiranka, O., Juaraez, B., Watson, M. A. \& Richard, O. A. (2003). Effect of cutting and storage on sensory traits of cantaloupe melon cultivars with extended postharvest shelf life. Journal of the Science of Food and Agriculture, 83(7), 702-708. http://dx.doi.org/10.1002/ jsfa. 1337 
Lamiranka, O., Kueneman, D., Ukuku, D., \& Bett-Garber, K. L. (2005). Effect of processing under ultraviolet light on the shelf life of fresh-cut Cantaloupe melon. Food Chemistry and Toxicology, 70(9), 534-539.

Lamiranka, O., Richard, O. A., \& Parker, A. (2002). Ultraviolet induced stress response in fresh cut cantaloupe. Phytochemistry, 60(1), 27-32. http://dx.doi.org/10.1016/S0031-9422(02)00048-1

Luna-Guzmán, I., Cantwell, M., \& Barrett, D. M. (1999). Fresh-cut cantaloupe: effects of $\mathrm{CaCl} 2$ dips and heat treatments on firmness and metabolic activity. Postharvest Biology and Technology, 17(3), 201-213. http://dx.doi.org/10.1016/S0925-5214(99)00048-4

Luna-Guzmán, I., \& Barrett, D. M. (2000). Comparison of calcium chloride and calcium lactate effectiveness in maintaining shelf stability and quality of fresh-cut cantaloupes. Postharvest Biology and Technology, 19(1), 61-72. http://dx.doi.org/10.1016/S09255214(00)00079-X

Mercier, J. (1997). Role of phytoalexins and other antimicrobial compounds from fruits and vegetables in postharvest disease resistance. In F. A. Thomas-Barbern \& R. J. Robin (Eds.), Photochemistry of fruit and vegetables. Neimer: C.H.I.P.S. p. 221-241.

O’Connor-Shaw, R. E., Roberts, R., \& Nottingham, S. M. (1996). Changes in sensory quality of sterile cantaloupe dice stored in controlled atmmospheres. Journal of Food Science, 61(4), 847-851. http://dx.doi.org/10.1111/j.1365-2621.1996.tb12217.x
Pan, Y. G., \& Zu, H. (2012). Effect of UV-C Radiation on the Quality of Fresh-cut Pineapples. Procedia Engineering, 37, 113-119. http:// dx.doi.org/10.1016/j.proeng.2012.04.212

Portela, S. I., \& Cantwell, M. I. (1998). Quality changes of minimally processed honeydev melons stored in air or controlled atmosphere. Postharvest Biology and Technology, 14(3), 351-357. http://dx.doi. org/10.1016/S0925-5214(98)00052-0

Portela, S. I., \& Cantwell, M. I. (2001). Cutting blaed sharpness affects appearance and other quality attributes of fresh-cut cantaloupe melon. Journal of Food Science, 66(9), 1265-1270. http://dx.doi. org/10.1111/j.1365-2621.2001.tb15199.x

Sams, C. E. (1999). Preharvest factors affecting postharvest texture. Postharvest Biology and Technology, 15(3), 249-254. http://dx.doi. org/10.1016/S0925-5214(98)00098-2

Supapwanich, S., \& Tucker, G. A. (2011). Physicochemical changes in fresh-cut Honeydew melon fruit during storage. African Journal of Agricultural Research, 6(12):2737-2742.

Turtoi, M. (2013). Ultraviolet light treatment of fresh fruits and vegetables surface: a review. Journal of Agroalimentary Processes and Technologies, 19(3), 325-337.

Wiley, R. C. (1994). Preservation methods for minimally processed refriferated fruits and vegetables. In R. C. Wiley (Ed.), Minimally processed refrigerated fruits and vegetables. New York: Chapman and Hall. p. 1-14. http://dx.doi.org/10.1007/978-1-4615-2393-2_1 